\title{
Awareness, perceptions, and preventive practices of COVID-19 among health workers in Tigray, North Ethiopia
}

\author{
Teferi Gebru Gebremeskel ${ }^{1}$ (1) $\cdot$ Kalayu Kiros ${ }^{2} \cdot$ Hailay Abrha Gesesew ${ }^{3,4} \cdot$ Paul R. Ward $^{3}$ \\ Received: 14 July 2020 / Accepted: 10 May 2021 / Published online: 17 July 2021 \\ (C) The Author(s), under exclusive licence to Springer-Verlag GmbH Germany, part of Springer Nature 2021
}

\begin{abstract}
Background Despite measures to reduce the spread of COVID-19 in the world, it is increasing day by day. Countries that implement good prevention strategies are less likely to be infected with COVID-19 than those that do not. Therefore, the aim of this study was to assess knowledge, attitude, and preventive practices toward COVID-19 early in the outbreak among health workers in Northern Ethiopia.

Methods A health facility-based cross-sectional study was conducted among health professionals working in public health centers and hospitals from April to May 2020. A simple random sampling technique was employed to select study respondents. Data were entered in Epi-info 7.1 and exported to SPSS version 20.00 for analysis. Simple descriptive summary statistics were done. Binary logistic regression was used to evaluate the factors of the principal defense practice.

Results A total of 403 health workers were included in the study making a response rate of $96 \%$. Of these, $79 \%$ and $87.9 \%$ of health care workers had good knowledge and a good attitude and $64.3 \%$ of health care practitioners had good practice in preventing COVID-19. Approximately $92.0 \%$ said that COVID-19 has no specific treatment and vaccine, while $54.8 \%$ of health care workers did not use the necessary personal protective equipment at all times. We found that being female [AOR 2.43, 95\% CI (1.50-3.94)], work experience of 2-5 years [AOR 2.44, 95\% CI (1.10-5.39)], news media as a source of information [AOR $7.11,95 \% \mathrm{CI}(3.07-16.49)$ ], social media as a source of information [AOR 4.59, 95\% CI (2.15-9.84)], and governmental website as a source of information [AOR 4.21, 95\% CI (2.15-8.27)] were reported as protective factors, and being single marital status [AOR $0.15,95 \% \mathrm{CI}(0.03-0.75)$ ] was reported as a risk factor toward the prevention of COVID-19.

Conclusion Most health workers scored good knowledge and attitude; nevertheless, a significant proportion of health workers had poor practice toward the prevention of COVID-19, including the use of PPE. Additionally, some groups of health professional had poor practices of implementing the public health measures, thus necessitating a call targeted at them to improve the prevention and control of COVID-19.
\end{abstract}

Keywords Awareness $\cdot$ Perception $\cdot$ Practice $\cdot$ COVID-19 $\cdot$ Health care worker

Teferi Gebru Gebremeskel

teferigebru12@gmail.com

1 Department of Reproductive Health, College of Health Sciences, Aksum University, Aksum, Ethiopia

2 School of Medicine, College of Medicine and Health Science, Aksum University, Aksum, Ethiopia

3 Discipline of Public Health, Flinders University, Adelaide, Australia

4 Department of Epidemiology, College of Health Sciences, Mekele University, Mekele, Ethiopia

\section{Introduction}

In December 2019, Wuhan, Hubei province, China, became the center of an outbreak of pneumonia of unknown cause, which later became known as a the novel coronavirus disease 19 (COVID-19) (Huang et al., 2020; Wang et al., 2020a, b). Globally, there were $31,867,173$ infections and 967,258 deaths as of 24 September 2020 (WHO Coronavirus (COVID-19) Dashboard, 20 September 2020). Africa had recorded 1,420,629 cases and 34,327 deaths as of 24 September 2020 (Control, 20 September 2020). The first reported coronavirus patient in Ethiopia, a Japanese citizen, was observed on 13 March 2020 ([@lia_tadesse], 14 March 2020a). There 
have been more than 71,083 cases and 1141 deaths in Ethiopia as of 23 September 2020 ([@ lia tadesse], 19 september 2020b). Tigray reported 5316 cases and 27 deaths as of 19 September 2020 (Bureau, 19 September 2020).

Several countries put public health measures in place to control the transmission of COVID-19. Nevertheless, the compliance with these measures is not to the desired level. Some of the reasons include long-term vulnerability, lack of personal protective equipment, overcrowding, lack of isolation facilities, contaminated environment, and possibly a lack of knowledge and understanding among health care workers (HCWs) (S. Jemal et al., 2019; Wang et al., 2020a, b; Wu \& McGoogan, 2020). Studies show that HCWs have $93.2 \%$ of good knowledge, [mean 8.43 (SD 1.78)] positive attitude, and $88.7 \%$ of good practice regarding COVID-19 (Saqlain et al., 2020). Reports from the health care professionals in Greece toward SARS-CoV-2 showed that $88.3 \%$ of the respondents had good knowledge and $71 \%$ of the participants agreed to temporary travel restrictions (Papagiannis et al., 2020). Cross-sectional studies in Egypt show that the average correct answer for COVID-19 prevention-related questions was $80.4 \%$ with a mean knowledge score of 18.5 \pm 2.7 out of 24 . Approximately $83.1 \%$ of the participants feared COVID-19, and $89.2 \%$ said they had a higher risk of COVID-19 compared to others (Wahed, Hefzy, Ahmed, \& Hamed, 2020).

There is no recent evidence of COVID-19 prevention practice of HCWs in Ethiopia in general and in Tigrai in particular. Early prevention of the disease before its entry has paramount importance. The level of knowledge, perception, and practice of health workers is indispensable to successful early prevention of the disease. This study aims to assess the knowledge, perception, and practice of HCWs about COVID-19 in the central zone of Tigrai, Ethiopia.

\section{Methods}

\section{Study setting}

The study was conducted by comprehensive referral in Saint Mary Hospital, which is located in the city of Aksum, from April to May 2020. Aksum city is located $1045 \mathrm{~km}$ away from Addis Ababa, the capital city of Ethiopia, and $262 \mathrm{~km}$ from Mekele the capital city of Tigray regional state. As such, the hospital can be designated as the most advanced medical facility, by all accounts, in the northern part of the country and that it stands as the second and third largest hospital in the regions. A health facility-based prospective study was conducted among health care personal to assess knowledge, attitude, and practice for coronavirus disease 19 (COVID-19).

\section{Participants}

Any health care worker with a list of 6 months is considered. All health care workers, including physicians, pharmacists, nurses, and laboratory technicians were included, while respondents who were a student or health care workers that had no willingness to participate in the study were excluded.

\section{Sample size and procedure}

The sample size was determined using formula single proportions since there is no similar study in Ethiopia. By taking the predetermined parameters of $50 \%(P=0.5$, because there is no similar study in Ethiopia) 95\% CI $\left.\left(\mathbf{Z}_{1-\alpha / 2}\right)=1.96\right)$ and $5 \%$ degree of marginal error (d). Finally, by adding a 5\% nonresponse rate, the required sample size became 403. A simple random sampling technique was employed to select study respondents.

\section{Operational definitions}

- Knowledge was dichotomized as good if the overall score was $>=60 \%$, and poor if $<60$ (Tadesse, Gebrewahd, \& Demoz, 2020; Zhong et al., 2020; Zhou et al., 2020). The knowledge questionnaire consisted of 15 questions, and participants who correctly answered more than nine questions scored as "good knowledge" and those who scored less than nine were categorized as "poor knowledge."

- The attitude was dichotomized as good if the overall score was $>=50 \%$, and poor if $<50$ (Tadesse et al., 2020; Zhong et al., 2020; Zhou et al., 2020). The perception questionnaire consisted of 11 questions, and participants who correctly answered more than six questions scored as "good perception" and those who scored less six than were categorized as "poor perception."

- The practice was dichotomized as good if the overall score was $>=50 \%$, and poor if $<50$ (Tadesse et al., 2020; Zhong et al., 2020; Zhou et al., 2020). The practice questionnaire consisted of 10 questions, and participants who correctly answered more than five questions scored as "good practice" and those who scored less than five were categorized as "poor practice."

\section{Data collection tools and techniques}

Data was collected by using an interviewer-administered and structured questionnaire adapted from WHO survey questions. The questionnaire includes socio-demographic, knowledge, attitude, and practice. 


\section{Data quality assurance and control}

Three data collectors and supervisors were recruited from another area outside of the study site, and they were given training for two days. The supervisors followed the process of data collection daily, checked the data completeness consistency, and communicated with principal investigators daily.

\section{Data processing and analysis}

After being coded, data were entered into Epi-info 7 and exported to SPSS version 20.00 for analysis. Simple descriptive summary statistics, and summarized by frequency, percentage, and mean were employed. Tables, charts, and graphs were used to present the results of the analyzed data. Bivariate logistic regression analysis was performed to assess the crude association between the exposure variables and outcome variables. Variables with $P$ value $<0.2$ were recruited for multivariate logistic regression analysis. Adjusted odds ratio with $95 \%$ of CI was calculated and $P$ values less than 0.05 were considered as a cut-off for the statistically significant association.

\section{Results}

A total of 403 health workers were included in the study making a response rate of $96 \%$. Among the participant mean age was $28.2 \pm 5.1$ years. The minimum and maximum age were 19 and 46 years, respectively. More than half $(51.7 \%)$ of the participants were male; female to male ratio was $1: 1.07$. The majority of the participants, $52.7 \%$, were single, $45.5 \%$ married, $1.8 \%$ divorced; $54.0 \%$ of participants were nurses, $20.7 \%$ physicians, 10.9 midwives, 9.0\% pharmacists, and $5.7 \%$ laboratory, technicians. The majority of the participants $(83.2 \%)$ were Tigrian in ethnicity. Except for one, all had heard about COVID-19 and $70.5 \%$ of them had training on COVID-19 (Table 1).
Table 1 Socio-demographic characteristic of health workers at comprehensive referral and St. Mary Hospital, Aksum, Ethiopia. $(n=403)$ April to May 2020

\begin{tabular}{|c|c|c|c|}
\hline Characteristics & & Frequency & Percent \\
\hline \multirow[t]{3}{*}{ Age } & $<=25$ & 104 & 26.9 \\
\hline & $26-29$ & 143 & 37.0 \\
\hline & $>30$ & 140 & 36.2 \\
\hline \multirow[t]{2}{*}{ Sex } & Male & 200 & 51.7 \\
\hline & Female & 187 & 48.3 \\
\hline \multirow[t]{3}{*}{ Marital status } & Single & 204 & 52.7 \\
\hline & Married & 176 & 45.5 \\
\hline & Divorced & 7 & 1.8 \\
\hline \multirow[t]{3}{*}{ Religion } & Orthodox & 372 & 96.1 \\
\hline & Muslim & 13 & 3.4 \\
\hline & Protestant & 2 & 0.5 \\
\hline \multirow[t]{3}{*}{ Ethnicity } & Tigray & 322 & 83.2 \\
\hline & Amara & 57 & 14.7 \\
\hline & Oromo & 8 & 2.1 \\
\hline \multirow[t]{5}{*}{ Profession } & Physician & 80 & 20.7 \\
\hline & Nurse & 209 & 54.0 \\
\hline & Midwifery & 41 & 10.6 \\
\hline & Pharmacy & 35 & 9.0 \\
\hline & Laboratory technician & 22 & 5.7 \\
\hline \multirow[t]{3}{*}{ Work experience in the year } & $<2$ years & 157 & 40.6 \\
\hline & $2-5$ years & 143 & 37.0 \\
\hline & $>=5$ years & 87 & 22.5 \\
\hline \multirow[t]{2}{*}{ Have heard about COVID-19 } & Yes & 386 & 99.7 \\
\hline & No & 1 & 0.3 \\
\hline \multirow[t]{2}{*}{ Training on COVID-19 } & Yes & 273 & 70.5 \\
\hline & No & 114 & 29.5 \\
\hline
\end{tabular}


Fig. 1 Knowledge of health care worker toward COVID-19

Fig. 2 Attitude of health care worker toward COVID-19

\section{Knowleadge level of HCW}

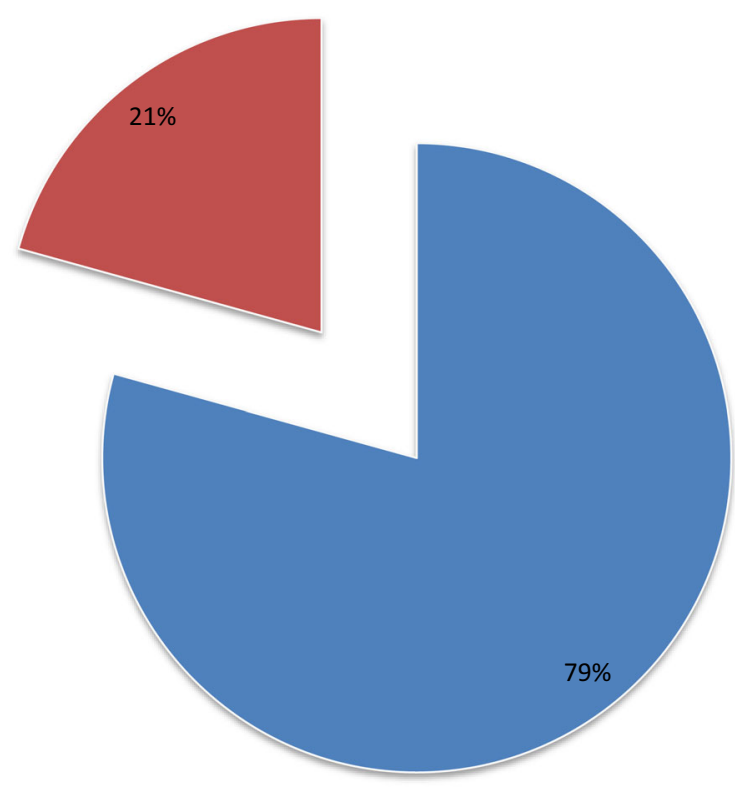

Good knowleadge

- Poor knowleage

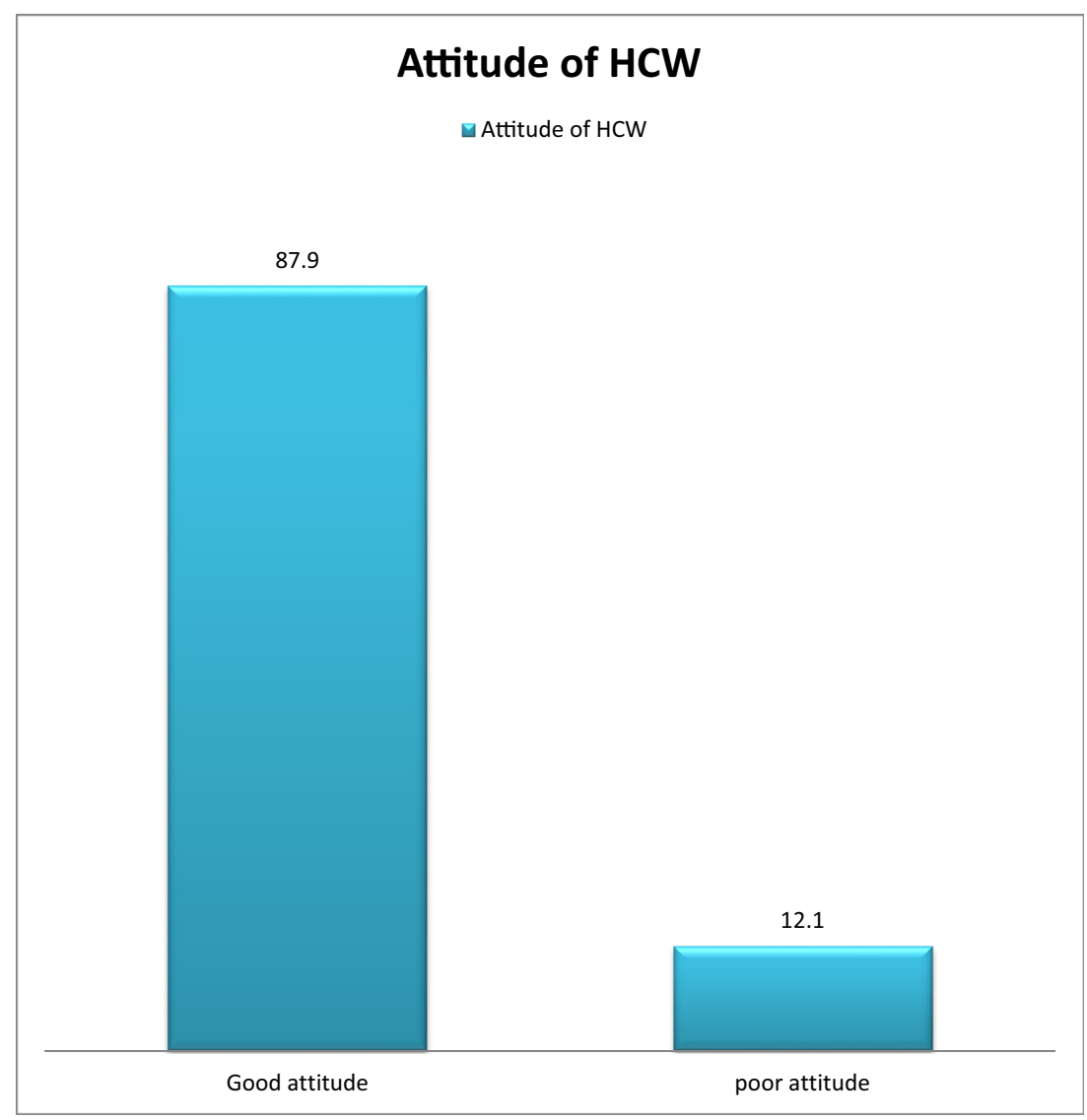




\section{Knowledge, attitude, and practice of HCWs toward COVID-19 and public health measures}

More than three fourth (79\%) of health workers were knowledgeable about COVID-19. The majority of participants, 92\%, knew that COVID-19 has no special treatment and vaccine (Fig. 1). The majority of $(87.9 \%)$ health workers had a good perception of COVID-19. Almost all participants (97.4\%) perceived that washing hands with soap and water was the best practice of COVID-19 prevention (Fig. 2). More than half $(64.3 \%)$ of health workers had good practice toward COVID-19 prevention. Almost all of the health workers (96.1\%) kept their hand hygiene (wash with soap or alcohol rub) consistently. Nearly half of health workers $(54.8 \%)$ did not use the necessary personal protective equipment at all times (Fig. 3).

\section{Factors associated with knowledge}

All variables were checked for the chi-square assumption and entered into the bivariate logistic regression model. Accordingly, age, sex, work experience in year, news media as source of information, social media as source of information, governmental website as source of information, family and friends as source of information had a $P$ value of $<0.2$ and fitted into multivariable analysis. In multivariable logistic regression analysis, work experience in the year and governmental website as a source of information were significantly associated with good knowledge of COVID-19. Participants with work experience between 2 and 5 years were two times (AOR 2.44, 95\%CI 1.10-5.39) more likely to be knowledgeable compared to participants with $>=5$ years of work experience. Those having a governmental website as a source of information were four times (AOR4.21, 95\% CI 2.15-8.27) more likely to be knowledgeable than those who did not (Table 2).

\section{Factors associated with attitude}

Age, ethnicity, news media and social media as a source of information, governmental website as a source of information, and family and friends as a source of information were included in the multivariable analysis. In multivariable logistic regression analysis, ethnicity, news media as a source of information, and social media as a source of information were significantly associated with a good perception of COVID19. Participants having news media as a source of information were seven times (AOR 7.11, 95\% CI 3.07-16.49) more likely to have a good perception toward COVID-19 than participants who did not attend news media. Exposure to social media (AOR 4.59, 95\% CI 2.15-9.84) was indicated to have a good perception than no exposure (Table 2).

\section{Factors associated with the practice}

All variables were checked for the chi-square assumption and entered into the bivariate logistic regression model. Accordingly, age, sex, marital status, ethnicity, news media as a source of information, and family and friends as a source of information had a $P$ value of $<0.2$ and fitted into multivariable analysis. In multivariable logistic regression analysis, sex and marital status were significantly associated with good practice of COVID-19 prevention.

It was indicated that males were two times (AOR 2.43 95\% CI 1.50-3.94) more likely to have good practice to prevent COVID-19 than females (Table 2).
Fig. 3 Practice of health care worker toward COVID-19

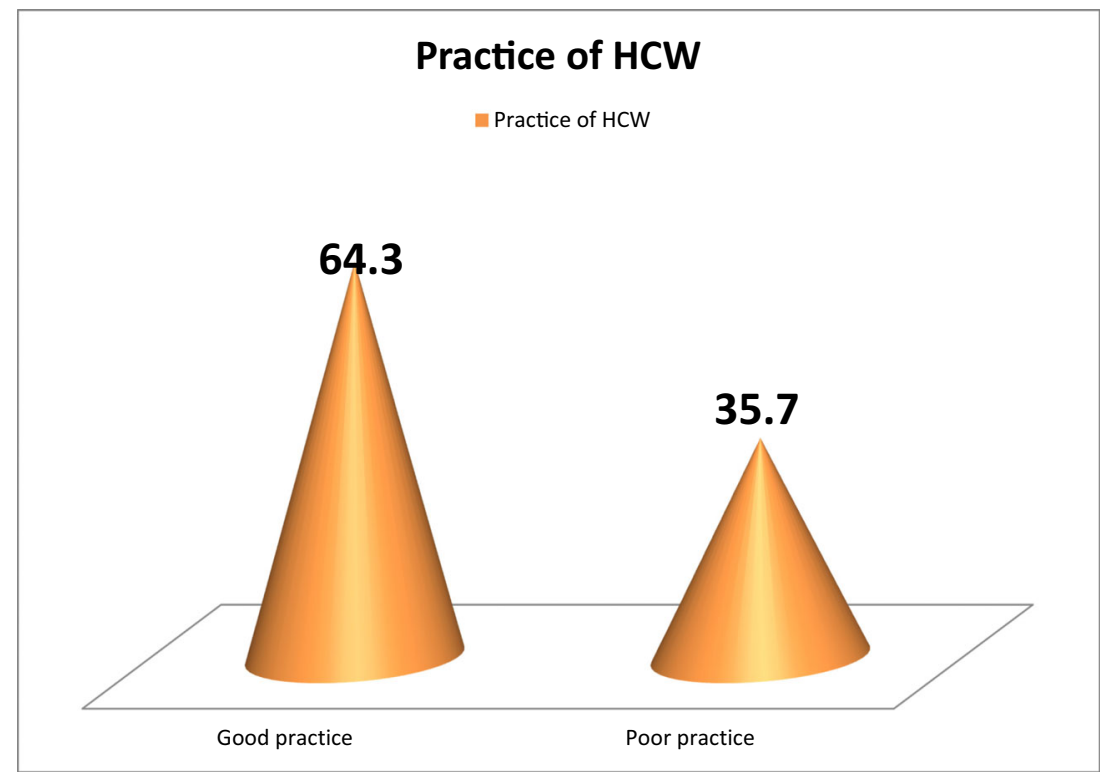


Table 2 Bivariate and multivariate logistic regression analysis of knowledge, attitude, and practice about COVID-19 of health workers among health workers of the Aksum referral at St. Mary Hospital, Tigrai, Ethiopia. $(n=403)$ April to May 2020

\begin{tabular}{|c|c|c|c|c|c|}
\hline \multirow[t]{2}{*}{ Variable } & & \multicolumn{2}{|c|}{ COVID-19 knowledge } & \multirow[t]{2}{*}{ COR } & \multirow[t]{2}{*}{ AOR } \\
\hline & & Good & Poor & & \\
\hline \multirow[t]{3}{*}{ Age } & $<=25$ & $34(32.7)$ & $70(67.3 \%)$ & $2.13(1.18-3.85)$ & $1.79(0.83-3.89)$ \\
\hline & $26-29$ & $20(14 \%)$ & $123(86 \%)$ & $0.71(0.38-1.35)$ & $0.61(0.30-1.23)$ \\
\hline & $>30$ & $26(18.6 \%)$ & $114(81.4 \%)$ & 1 & 1 \\
\hline \multirow[t]{2}{*}{ Sex } & Male & $167(83.5)$ & $33(16.5)$ & 1 & 1 \\
\hline & Female & $140(74.9)$ & $47(25.1)$ & $0.59(0.39-0.97)$ & $0.68(0.39-1.19)$ \\
\hline \multirow[t]{3}{*}{ Work experience in the year } & $<2$ years & $32(20.4 \%)$ & $125(79.6 \%)$ & $1.46(0.72-2.95)$ & $1.66(0.67-4.13)$ \\
\hline & $2-5$ years & $35(24.5 \%)$ & $108(75.5 \%)$ & $1.86(1.09-3.72)$ & $2.44(1.10-5.39)^{*}$ \\
\hline & $>=5$ years & $13(14.9 \%)$ & $74(85.1 \%)$ & 1 & 1 \\
\hline \multirow[t]{2}{*}{ News media as a source information } & Yes & $278(80.8 \%)$ & $66(19.2 \%)$ & $2.03(1.01-4.06$ & $1.60(0.74-3.48)$ \\
\hline & No & $29(67.4 \%)$ & $14(32.6 \%)$ & 1 & 1 \\
\hline \multirow[t]{2}{*}{ Social media as a source information } & Yes & $245(82.2 \%)$ & $53(17.8 \%)$ & $2.01(1.17-3.46)$ & $1.73(0.91-3.27)$ \\
\hline & No & $62(69.7 \%)$ & $27(30.3 \%)$ & 1 & 1 \\
\hline \multirow[t]{2}{*}{ Governmental website as a source information } & Yes & $182(89.2 \%)$ & $22(10.8 \%)$ & $3.84(2.24-6.59)$ & $4.21(2.15-8.27)^{* *}$ \\
\hline & No & $125(68.3 \%)$ & $58(31.7 \%)$ & 1 & 1 \\
\hline \multirow[t]{2}{*}{ Family and friends as source information } & Yes & $146(82.5 \%)$ & $31(17.5 \%)$ & $1.43(0.87-2.37)$ & $0.58-(0.29-1.14)$ \\
\hline & No & $161(76.7 \%)$ & $49(23.3 \%)$ & 1 & 1 \\
\hline \multirow{2}{*}{\multicolumn{2}{|c|}{ Variable }} & \multicolumn{2}{|c|}{ COVID-19 Attitude } & COR & AOR \\
\hline & & Good & Poor & & \\
\hline \multirow[t]{3}{*}{ Age } & $<=25$ & $92(88.5 \%)$ & $12(11.5 \%)$ & $0.70(0.33-1.49)$ & $0.74(0.31-1.76)$ \\
\hline & $26-29$ & $130(90.9 \%)$ & $13(9.1 \%)$ & $0.53(0.26-1.1)^{*}$ & $0.59(0.26-1.37)$ \\
\hline & $>30$ & $188(84.3 \%)$ & $22(15.7 \%)$ & 1 & 1 \\
\hline \multirow[t]{2}{*}{ News media as a source information } & Yes & $316(91.9 \%)$ & $28(8.1 \%)$ & $8.94(4.37-18.27)^{* *}$ & $7.11(3.07-16.49)^{* *}$ \\
\hline & No & $24(55.8 \%)$ & $19(44.2)$ & 1 & 1 \\
\hline \multirow[t]{2}{*}{ Social media as a source information } & Yes & 278(93.3) & $20(6.7 \%)$ & $6.05(3.19-11.49)^{* *}$ & $4.59(2.15-9.84)^{* *}$ \\
\hline & No & $62(69.7 \%)$ & $27(30.3 \%)$ & 1 & 1 \\
\hline \multirow[t]{2}{*}{ Governmental website as a source information } & Yes & $191(93.6 \%)$ & $13(6.4 \%)$ & $3.35(1.71-6.58)^{* *}$ & $1.53(0.66-3.54)$ \\
\hline & No & $149(81.4 \%)$ & $34(18.6 \%)$ & 1 & 1 \\
\hline \multirow[t]{2}{*}{ Family and friends as source information } & Yes & $170(96 \%)$ & $7(4 \%)$ & $5.71(2.49-13.11)^{* *}$ & $2.25(0.81-6.29)$ \\
\hline & No & $170(81 \%)$ & $40(19 \%)$ & 1 & 1 \\
\hline \multirow{2}{*}{\multicolumn{2}{|c|}{ Variable }} & \multicolumn{2}{|c|}{ Practice to ward COVID-19 } & COR & AOR \\
\hline & & Good & Poor & & \\
\hline \multirow[t]{3}{*}{ Age } & $<=25$ & $70(67.3 \%)$ & $34(32.7 \%)$ & $0.71(0.42-1.20)^{*}$ & $1.34(0.71-2.53)$ \\
\hline & $26-29$ & $96(67.1 \%)$ & $47(32.9 \%)$ & $0.71(0.44-1.16)^{*}$ & $0.86(0.51-1.45)$ \\
\hline & $>30$ & $83(59.3 \%)$ & $57(40.7 \%)$ & 1 & 1 \\
\hline \multirow[t]{2}{*}{ Sex } & Male & $111(55.5 \%)$ & $89(45.5 \%)$ & $2.26(1.47-3.47)^{* *}$ & $2.43(1.50-3.94)^{* *}$ \\
\hline & Female & $138(73.8 \%)$ & $49(26.2 \%)$ & 1 & \\
\hline \multirow[t]{3}{*}{ Marital status } & Single & $138(67.6 \%)$ & $66(32.4 \%)$ & $0.36(0.08-1.65)^{*}$ & $0.15(0.03-0.75)^{*}$ \\
\hline & Married & $108(61.4 \%)$ & $68(38.6 \%)$ & $0.47(0.10-2.18)$ & $0.26(0.05-1.28)$ \\
\hline & divorced & $3(42.9 \%)$ & $4(57.1 \%)$ & 1 & 1 \\
\hline \multirow[t]{2}{*}{ News media as a source information } & Yes & $227(66.0 \%)$ & $117(44.0 \%)$ & $1.85(0.98-3.51)^{*}$ & $1.65(0.81-3.36)$ \\
\hline & No & $22(51.2 \%)$ & $21(48.8 \%)$ & 1 & 1 \\
\hline Family and friends as source information & Yes & $119(67.2 \%)$ & $58(32.8 \%)$ & $1.26(0.83-1.92)$ & $1.13(0.71-1.80)$ \\
\hline & No & $130(61.9 \%)$ & $80(38.1 \%)$ & 1 & 1 \\
\hline
\end{tabular}

$* P$ value $<0.05, * * P$ value $<0.001, C O R$ crude odds ratio, $A O R$ Adjusted odds ratio

\section{Discussion}

This study aimed to assess knowledge, attitude, and practice toward the prevention and control of the COVID-19 outbreak among health workers in Northern Ethiopia. We found that the majority of health workers had scored good knowledge (79\%) regarding COVID-19 and related public health measures, as opposed to other findings from studies in Iran, Henan China, and Pakistan (Erfani, Shahriarirad, Ranjbar, Mirahmadizadeh, \& Moghadami, 2020; Saqlain et al., 2020; Zhou et al., 2020). The difference could be due to the frequency and focus of presentation of COVID in the media and public in these 
countries. The commitment and leadership of the government to put focus on informing the public about the pandemic may also be another reason for the difference. This builds on the finding on the source of knowledge about COVID-19, which is similar to the study conducted in Chinese residents (Zhong et al., 2020). Most health care workers get information from the news media (89\%) and social media (77\%) about COVID19. Interestingly, this finding differs from the study in Saudi Arabia, which indicates that the ministry of health website is one of the main sources of information (Asaad, El-Sokkary, Alzamanan, \& El-Shafei, 2020).

Several variables predicted the level of knowledge regarding COVID-19 in our setting. Participants with work experience between 2 and 5 years were two times more likely to know compared to participants with $>=5$ years of work experience. This is because mobile internet and social media or technology (Facebook, Youtube, Telegram, and Twitter) are easily accessible to most health professionals at home and in the workplace. Those having a governmental website as a source of information were four times more likely to know than those who did not, which is in agreement with a study conducted in Saudi Arabia where most health workers have access to information about COVID-19 and other infectious diseases from the Ministry of Health website (Abbag et al., 2018; Asaad et al., 2020). This implied that the Ethiopian Government and the Ministry of Health need to use the governmental website to disseminate information to HCWs.

In this study, the majority of (87.9\%) health workers had a good perception of COVID-19. Almost all participants (97.4\%) perceived that washing hands with soap and water was the best practice of COVID-19 prevention. The majority of health care workers, $89.4 \%$, recognized that COVID-19 is a fatal disease. Our study also revealed that participants having news media as a source of information and exposure to social media were associated with good perception toward COVID19. This is consistent with other studies where social media, if used wisely, can serve as a powerful tool to change people's behavior and improve the health of individuals and nations (Sahni \& Sharma, 2020). This is because mobile internet and social media or technology (Facebook, Youtube, Telegram, and Twitter) are easily accessible to most health professionals at home and in the workplace. This implied that the Ethiopian Government and the Ministry of Health need to use news and social media to disseminate information to HCWs.

More than half (64.3\%) of health workers had good practice toward COVID-19 prevention. Almost all of the health workers $(96.1 \%)$ kept hand hygiene (wash with soap or alcohol rub) consistently. This is similar to the findings of studies conducted in China and the United Arab Emirates (B. Jemal et al., 2020; Shi et al., 2020; Zhong et al., 2020; Zhou et al., 2020). Nearly half of health workers $(54.8 \%)$ did not use the necessary PPE at all times, maybe due to lack of PPE, not comfortable using the PPE, negligence, lack of safety and health education, and lack of knowledge and practice. Males were two times more likely to have good practice to prevent COVID-19 than females; interestingly, this finding differs from previous findings, and we found a significant association between male gender and potentially dangerous practices toward COVID-19 (Cobey, Laan, Stulp, Buunk, \& Pollet, 2013; Duell et al., 2018; Pawlowski, Atwal, \& Dunbar, 2008; Zhong et al., 2020). This is because of the male gender are more likely to engage in risk-taking behaviors.

\section{Limitations of this study}

The study has the following limitations. First, the nature of the study could not confirm the cause and effect relationship. Second, there may be an information bias given the data were collected from self-reports. Third, this study was only conducted in one hospital and may not necessarily be generalized to the entirety of Ethiopia. Fourth, health workers were the study participants and the level of knowledge, perception, and practice may be different from the public.

\section{Conclusions}

Mosthealthworkershavescoredgoodknowledgeandattitude; nevertheless, a significant proportion of health workers had poor practice toward the prevention of COVID-19, including theuseofPPE.Additionally,somegroupsofhealthprofessional had poor practices of implementing the public health measures, thus necessitating a call targeted at them to improve the prevention and control of COVID-19. The majority of health workers do not use the necessary personal protective equipmentatall times. Work experience, governmental website as a sourceofinformation, andsexwereprotective factors, andethnicity and marital status were risk factors toward COVID-19 and related publichealth measures. These indicate targetareas andgroupsofhealthworkerstofocusontopreventthespread of the coronavirus.

Abbreviations CDC, Center of Disease Control; COVID-19, Coronavirus Disease-2019; MERS, Middle East Respiratory Syndrome; SARS, Severe Acute Respiratory Syndrome; SARS-COV2, Severe Acute Respiratory Syndrome Corona Virus 2; WHO, World Health Organization; CI, Confidence intervals; KAPs, Knowledge, attitudes, and practices; OR, Odds ratio; $\mathrm{HCW}$, Health care worker

Acknowledgments We are highly indebted to all participants of the study, and we also thank the administrative bodies at all levels who endorsed us to undertake this study.

Availability of data and materials All relevant data are within the paper. The SPSS data of individual patients are not permitted to be provided to 
other bodies, as outlined by the Ethics Committee who approved the study. However, Teferi (teferigebru12@gmail.com) can provide an anonymized data set for researchers who need further clarification.

Authors contributions TG and KK designed the study and performed the statistical analysis, drafted the paper, data analysis, and read and approved the final paper.

\section{Declarations}

Ethical approval Ethical clearance was obtained from the Institutional Review Committee (IRC) of the College of Medicine and Health Sciences, University of Aksum. A permission letter was received from those administrative bodies of the health facility's verbal consent.

Consent to participate Written consent was obtained from all participants after they were informed on the purpose of the study.

Consent to publish Not Applicable.

Competing interests The authors declare they have no conflict of interest.

\section{References}

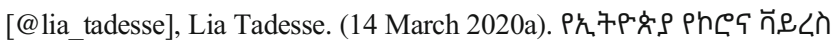

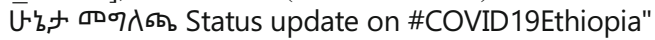

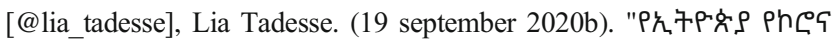

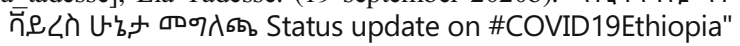

Abbag HF, El-Mekki AA, Bshabshe A, Ali AA, Mahfouz AA, Al-Dosry AA, Mirdad RT et al (2018) Knowledge and attitude towards the Middle East respiratory syndrome coronavirus among healthcare personnel in the southern region of Saudi Arabia. J Infect Pub Health 11(5):720-722

Asaad AM, El-Sokkary RH, Alzamanan MA, El-Shafei M (2020) Knowledge and attitudes towards Middle East respiratory syndrome-coronavirus (MERS-CoV) among health care workers in south-western Saudi Arabia. East Mediterr Health J 26(4):435442

Bureau, Tigray Regional Health (2020) Update reported coronavirus patient (19 September 2020)

Cobey KD, Laan F, Stulp G, Buunk AP, Pollet TV (2013) Sex differences in risk taking behavior among Dutch cyclists. Evol Psychol 11(2): 147470491301100206

Control, European Centre for Disease Prevention and Control (2020). COVID-19 situation update worldwide. 20 September 2020. https://www.ecdc.europa.eu/en/geographical-distribution-2019ncov-cases

Natasha D, Steinberg L, Icenogle G, Chein J, Chaudhary N, Di Giunta L et al. (2018) Age patterns in risk taking across the world. J Youth Adolesc 47(5): 1052-1072

Erfani A, Shahriarirad R, Ranjbar K, Mirahmadizadeh A, Moghadami M (2020) Knowledge, attitude and practice toward the novel coronavirus (COVID-19) outbreak: A population-based survey in Iran. PLoS One 15(9):e0238492
Huang C, Wang Y, Li X, Ren L, Zhao J, Hu Y et al (2020) Clinical features of patients infected with 2019 novel coronavirus in Wuhan, China. Lancet 395(10223):497-506

Jemal B, Ferede ZA, Mola S, Hailu S, Abiy S, Wolde GD et al. (2020) Knowledge, attitude and practice of healthcare workers towards COVID-19 and its prevention in Ethiopia: a multicenter study. Res Sq. https://doi.org/10.21203/rs.3.rs-29437/v1

Jemal S, Zeleke M, Tezera S, Hailu S, Abdosh A, Biya M, Abduljelil S (2019) Health care workers' knowledge, attitude and practice towards infection prevention in Dubti referral hospital, Dubti, north east Ethiopia. Int J Infect Dis Ther 3(4):66

Papagiannis D, Malli F, Raptis DG, Papathanasiou IV, Fradelos EC, Daniil Z et al (2020) Assessment of knowledge, attitudes, and practices towards new coronavirus (SARS-CoV-2) of health care professionals in Greece before the outbreak period. Intl J Environ Res Pub Health 17(14):4925

Pawlowski B, Atwal R, Dunbar RIM (2008) Sex differences in everyday risk-taking behavior in humans. Evol Psych 6(1): 147470490800600104

Sahni H, Sharma H (2020) Role of social media during the COVID-19 pandemic: beneficial, destructive, or reconstructive? Intl J Acad Med 6(2):70

Saqlain M, Munir MM, ur Rehman S, Gulzar A, Naz S, Ahmed Z et al. (2020) Knowledge, attitude, practice and perceived barriers among healthcare professionals regarding COVID-19: A Cross-sectional survey from Pakistan. J Hosp Infect 105(3):419-423

Shi Y, Wang J, Yang Y, Wang Z, Wang G, Hashimoto K, et al. (2020) Knowledge and attitudes of medical staff in Chinese psychiatric hospitals regarding COVID-19. Brain Behav Immun Health 4: 100064

Tadesse DB, Gebrewahd GT, Demoz GT (2020) Knowledge, attitude, practice and psychological response toward COVID-19 among nurses during the COVID-19 outbreak in northern Ethiopia, 2020. New Microbes New Infect38:100787

Wahed WYA, Hefzy EM, Ahmed MI, Hamed NS (2020) Assessment of knowledge, attitudes, and perception of health care workers regarding COVID-19, a cross-sectional study from Egypt. J Commun Health 45(6):1242-1251

Wang C, Horby PW, Hayden FG, Gao GF (2020a) A novel coronavirus outbreak of global health concern. Lancet 395(10223):470-473

Wang J, Zhou M, Liu F (2020b) Reasons for healthcare workers becoming infected with novel coronavirus disease 2019 (COVID-19) in China. J Hosp Infect 105(1):100-101

WHO Corona virus disease (COVID-19) Dashboard (20 September, 2020). https://covid19.who.int/

Wu Z, McGoogan JM (2020) Characteristics of and important lessons from the coronavirus disease 2019 (COVID-19) outbreak in China: summary of a report of 72314 cases from the Chinese Center for Disease Control and Prevention. Jama 323(13):1239-1242

Zhong B-L, Luo W, Li H-M, Zhang Q-Q, Liu X-G, Li W-T, Li Y (2020) Knowledge, attitudes, and practices towards COVID-19 among Chinese residents during the rapid rise period of the COVID-19 outbreak: a quick online cross-sectional survey. Int J Biol Sci 16(10): 1745

Zhou M, Tang F, Wang Y, Nie H, Zhang L, You G, Zhang M (2020) Knowledge, attitude and practice regarding COVID-19 among health care workers in Henan, China. J Hosp Infect 105(2):183-187

Publisher's note Springer Nature remains neutral with regard to jurisdictional claims in published maps and institutional affiliations. 